her interpretation of the Middle Old Red Sandstone break in Ireland, or with her over-simplified account of Upper Devonian events in South Wales.

No system in the British Isles has been so intensively studied as the Carboniferous, and the account of this is a model of concision. Comment is required only on minor points. The author should have made it clear that some of the Namurian Grits of the Pennine area have been derived from the south, off St. Georges Land. The relationship of the succession in the South Wales Coalfield to the Culm of Devon and Cornwall is not clarified. The knowledge that a part of the Coalfield succession is of southerly origin should have invited a closer analysis.

In Germany and the Netherlands there are Permian and Triassic standards of great importance to an understanding of the British succession. Dr Rayner refers to these standards, but is hampered in her application of them to Britain by the difficulties of dating the British rocks. The depositional break at the base of the British Keuper is mentioned but is accorded no particular significance. It now seems likely, from palynological and other work done on the mainland and in connexion with North Sea explora. tion, that the Keuper Sandstone is of late Bunter age. The whole early "Keuper" sequence may reveal in Britain events closely connected in Germany and the Netherlands with the Muschelkalk transgression. Other kinds of environment seem preferable to Dr Rayner's Keuper "plains and lakes".

We find the author on firmer ground when it comes to the Jurassic, Cretaceous and Cainozoic rocks, all of which have been much studied. The account of the Jurassic System is unexceptionable and mercifully brief. Only one comment is due as regards the Cretaceous. Dr Rayner assigns the final submergence of the London Platform to Gault times; the sedimentological evidence, however, points to a connexion by at the latest the end of the Lower Albian. A stronger exception must be taken to the interpretation placed on the Reading Beds which begin the Cainozoic in the area west of London. At least the basal gravel of this formation is fully marine, and there is evidence that the higher rocks may be of littoral origin. The Palaeocene transgression was probably as widespread as the later, though more substantial, Ypresian one.

Too often the British geologist dismisses Plio-Pleistocene deposits as a subject of little concern. This is an unfortunate view, for herein is to be found a greater range of geological phenomena than in perhaps any older beds. Moreover, the late Pleistocene deposits afford a natural laboratory in which process and geological resultant can be closely matched. The task of outlining the PlioPleistocene of Britain has not been shirked, but the complexity of the subject finally defeats Dr Rayner. Once the Crags have been dealt with, the treatment falls below the high standard set in earlier chapters.

It would be ungracious to deny Dr Rayner the praise due to an important work, yet false to suppose that other interpretations of the subject of stratigraphy did not exist. It is fair to conclude that Dr Rayner aligns herself perhaps more with the "classical" than with some modern conceptions of the subject. This viewpoint invites a number of questions which all geologists should debate with themselves from time to time. Can there be a stratigraphy of the British Isles, or is this yet another conceit of the island race? What of the geological units-especially the Caledonides and Hercynides-of which the British Isles once formed a part? Should a stratigraphy be developed for these units rather than geographical or political ones? What place should be given to the relationship between sedimentation and tectonics? If the connexion is recognized-and this seems unavoidable-then unconformities should be explored in as much detail as sedimentary formations. Further, isopachous, facies and sedimentdispersal maps would have an important place in any stratigraphical account. Can a rehearsal of outerop, zone and lithology be considered enough? J. R. L. AIILN

\section{ATTRACTION OF EARTH}

The Gravity Field of the Earth from Classical and Modern Methods

(International Geophysics Series, Vol. 10.) By Michele Caputo. Pp. xiv + 202. (New York : Academic Press, Inc. ; London : Academic Press, Inc. (London), Ltd., 1967.) $78 s$.

IN this book Dr Caputo provides a useful exposition of the framework of mathematical theory needed in studies of terrestrial gravity and the external gravitational field. The theory expounded in the first part of the book is applicable mainly to measurements made on the Earth's surface, by the traditional methods of gravity survey and geometrical geodesy. The theory is developed in terms of ellipsoidal co-ordinates, and gives in closed form the potential of a rotating planet whose gravity field has an ellipsoid of revolution as an equipotential surface. The practical problems to which the theory applies include the international gravity formula and hydrostatic equilibrium figures. In the remaining seventy pages of the book the theory of Earth satellite orbits is developed, generally on quite conventional lines, by expanding the gravitational potential in Legendre polynomials. This section ends with a review of recent determinations of the geoid by analysis of satellite observations.

The book is written in a pleasant style and the virtues of the "ellipsoidal approach" are well brought out. Certainly this approach has advantages, but it also has deficiencies, as the author tacitly admits by not adopting it when he comes to treat satellites. The book is well produced, and expensive; misprints are fairly frequent, but usually trivial.

D. G. KING-HELE

\section{MODELS IN STRUCTURAL GEOLOGY}

\section{Gravity, Deformation and the Earth's Crust}

As Studied by Centrifuged Models. By Hans Ramberg. Pp. ix + 214. (London: Academic Press, Inc. (London), Ltd.; New York: Academic Press, Inc., 1967.) 57s. 6d.; $\$ 11$.

THE use of scale models to investigate the mechanical processes in the Earth's crust has had limited success. This is because of the well known difficulty of scaling down the dimensions, the time scale, the forces and the mechanical properties in the same model. One of the greatest hindrances has been the lack of a sufficiently large body force in the model to represent gravity. This has been a serious difficulty, for gravity has a profound influence on the formation of most geological structures and it is the controlling factor in some of them.

Ramberg has made an important contribution to structural geology by introducing the centrifuge technique into scale model investigations. This enables centrifugal accelerations of up to $3,000 \mathrm{~g}$ to be applied, which can provide at last a realistic representation of gravitational body forces in the crust. The central theme of the book is the application of this technique to problems such as the rise of salt domes (so important in the North Sea oil hunt) and the uplift of mountain ranges. Some noncentrifuged models are also included, and the experimental work is backed up by theoretical calculations which are mainly based on Newtonian viscosity.

The book contains much important information for the structural geologist. One can mention the demonstration by theory and experiment that the downbuckling mechanism of geosyncline subsidence cannot work, and the beautiful scale model experiments of salt dome rise. There is also controversial matter, such as Ramberg's preference for vertical body forces to horizontal compression as the primary mechanism for mountain building.

Professor Ramberg is to be congratulated on his important contribution to genlogy. The same cannot be said. 